\title{
Resilience, fear of COVID-19 and their relationship with cognitive functioning and mood: a study on the administrative staff of the University of Western Macedonia, Greece
}

\author{
Katerina Flora*, Triantafyllia Georgiadou , Kalliopi Megari , Iraklis Grigoropoulos , Vasilis Chasiotis
}

\begin{abstract}
Background: The present study examines the relationship between resilience, mood, fear for Covid-19 and cognitive functioning during pandemic Covid-19.

Methods: A cross-sectional web-based study was conducted from December 2020 to January 2021 among the administrative staff of the University of Western Macedonia, Greece. Data was collected using the Connor-Davidson Resilience Scale (CD-RISC), Depression, Anxiety, and Stress (DASS 21), fear of Covid-19 scales (FCV-19S), and Cognitive functioning self-assessment scale (CFSS). Univariate, bivariate, and multivariate analysis was performed using an independent Sample T-Test, Chi-Square Test, One-way ANOVA, Mann-Whitney U Test, Kruskal-Wallis H Test, Spearman's Rank-Order Correlations, Pearson product-moment correlations, and Simple Linear Regression. SPSS version 22 was used for data analysis and the statistical significance was considered at less than 0.05.

Results: Results: Data of 88 university's administrative staff has undergone final analysis. Most of the respondents were females $(78.4 \%)$, married $(61.3 \%)$, middle-aged group $(64.8 \%)$, held a post-graduate degree $(56.8 \%)$ and $94.3 \%$ stated that they had not been sick with Covid-19. Our findings showed that the middle-aged group has statistically significantly higher fear on Covid-19 $(P=0.046)$, and more care of personal hygiene, stress $(P=0.040)$, than the young age group respectively. Women had a statistically significantly higher restriction to physical contact compared to men $(P=0.042)$, however, men had statistically significantly more trusted the results of clinical trials of Covid-19 vaccines than women $(P=0.039)$, respectively. There was statistically significant and negative correlation between Resilience (CD) and cognitive functioning $(r=-0.412, n=87, P<0.001)$. Furthermore, the result of a simple linear regression showed that an increase of one in $C D$ corresponded to a 0.287 decrease in cognitive functioning.
\end{abstract}

Conclusion: It is vital to continue monitoring the psychological and cognitive effects of the Covid-19 pandemic.

Keywords: COVID-19, Resilience, Fear of COVID-19, Mood, Cognitive Functioning, Administrators, Greece

\section{Background}

Resilience has been recognized in recent decades as an important variable that explains the ability to grow normally in the face of adverse conditions and to cope with all kinds of adversity [1-4]. It also explains how to deal effectively with threatening situations and/or recover from a traumatic event. Initially, the concept of resilience could explain why -although they grew up in disadvantaged environments- many children developed very positive traits [5-8]. The research then turned to the study of protective factors $[9,10]$ and interventions that are guided by the concept of resilience and promote adequacy and health. In recent years, genetic, epigenetic, developmental,

*Correspondence: katerinaflora@hotmail.com

${ }^{1}$ Department of Psychology, University of Western Macedonia, Florina, Greece Full list of author information is available at the end of the article psychosocial interactions have been studied [3]. In the context of the varied impact of difficult experiences on our lives, the possible positive effects ("Stress is enhancing mindset") are also studied. Various research, e.g., examines stress's association with positive emotions and physical alertness [11]. In the covid19 pandemic, resilience was one of the first concepts to arouse the interest of researchers, as most people worldwide were called upon to cope with unprecedented conditions that threatened their physical and mental health. Its protective role was once again confirmed. High resilience was associated with lower rates of anxiety, stress, depression, and fear [12]. At the same time, it was emphasized that increasing resilience requires improving other parameters such as increasing the level of positive emotions, sleep quality, and job satisfaction, especially in populations that are more burdened during this period, such 
as health workers [13]. It is also essential that the planned interventions are multifaceted, targeting many related populations, e.g., adolescents-adults [2] or employersemployees. As part of the extensive Covid-19 research activity that has affected all countries worldwide, the fear of the Covid19 variable was extensively assessed. This variable is particularly important as citizens around the world are faced with an unprecedented and uncertain situation. Fear can have many dimensions, such as the fear of being infected by ourselves and our people, fear of our work or the future. As expected, the fear of Covid-19 has often been studied in conjunction with other mood variables such as anxiety, depression, or positive emotions. Fear was positively associated with psychological distress, while the latter is predicted by other conditions such as pre-existing mental disorder, depression, smoking, and alcohol use [14-17]. Health-related stress and the widespread use of technology and social media predict high levels of fear [18]. Fear and anxiety can affect both oneself and family members and are exacerbated by additional concerns about work, problems with one's spouse and children due to quarantine, and forced teleworking from home. [19]. The importance of psychosocial and economic factors was also highlighted, as were women and those who had reduced access to health services due to financial hardship that was more psychologically burdened [15,20]. Health sector employees, especially those dissatisfied with their job, did not receive any information on Covid-19. Moreover, rates of fear were higher among part-time employees. It is worth mentioning that women had higher rates of negative emotions in all studies [20]. Particularly increased research activity was presented regarding the cognitive functioning and the effect of Covid-19 on it. Regarding people who have dementia or mild cognitive impairment, a decrease in their level of independence and/or memory deterioration was found, while deterioration of wellbeing levels was also observed in the caregivers of these patients [21-24]. One category of research, however, focused on the cognitive characteristics of people with Covid-19. Cognitive deficits such as memory impairment are observed, and the possibility of long-term neurological consequences is investigated [25-27]. The research activity in Greece around the psychological, neurological, and social consequences of covid 19 increased following the global trend [21,22, 24,28-31]. Most of the findings seem to confirm those of the rest of the literature. However, the resilience variable or the combination of this important factor with other variables, such as fear, mood, and cognitive functioning, has not been sufficiently studied in both local (Greek literature) and international literature. The present study aims to point out the relationship between resilience, fear of Covid 19, mood (depression, anxiety, stress), and cognitive functioning in the University of Western Macedonia administrators

\section{Methods}

Study design and background

A cross-sectional and web-based survey was conducted from December 2020 to January 2021, during the Covid-19 pandemic and while the Western Macedonia university's geographic region was under Covid-19 restrictions, including the obligatory university's transition exclusively to synchronous online courses. Due to Covid-19 restrictions, data were collected via an internet survey. Participants were informed about the study via email, including the link to the survey, and were asked to complete the questionnaires online. The study was designed in accordance with national and international research ethics guidelines and was approved by the university's Research Ethics Committee (approval number: 24/2021). Participation in the study was voluntary, with no tangible or intangible reward offered to the participants. To ensure participants' confidentiality, participation in the study was anonymous, and participants had to read and sign an informed consent form before taking part in data collection. The survey took approximately 20 to 30 minutes to complete, and all study data were collected simultaneously. First, participants were asked a series of questions concerning Covid-19. Namely, whether they adopt safety and checking behaviors (e.g., I clean/disinfect the objects that I use, I take care of my personal hygiene, I use personal protective equipment, I check myself for COVID-19, I have restricted physical contact with other people), the sources of information they trust as well as their trust in science and research related with the new coronavirus ( e.g., I always trusted science, I trust Covid-19 vaccine research, I feel confident about the Covid-19 vaccine and I will get vaccinated as soon as it is available, I listen to the doctors' recommendations on battling Covid-19) as well as the level of trust in 12 possible sources of information (e.g., WHO, the National Public Health Organization, other experts, the government, friends and family, social media). Then, to assess the relationship between resilience, depression, anxiety and stress, fear of Covid-19 and cognitive functioning, they were asked to complete the Connor-Davidson resilience scale [34], the DASS 21 [35], the fear of Covid-19 scale [38] as well as CFSS [40]. Participants were free to answer the questionnaires in any order. To identify any demographic-related differences as well as the relationship between fear of Covid-19, negative affect, resilience, cognitive functioning, and trust, a series of between-group comparisons were performed alongside correlations, tests of association, and linear regressions.

\section{Inclusion and exclusion criteria}

All the administrative staff, both gender and willing to participate have been included in the study. However, the incomplete data and those not willing to participate have been excluded from the study.

\section{Sample size calculation}

A universal sampling technique was recruited to collect the data from the administrative staff of the institution. We made repeated reminders once a week. We gathered 88 participants out of 131 registered staff giving a response rate of $67.2 \%$.

\section{Study instruments \\ Resilience}

The Connor-Davidson Resilience Scale (CD-RISC) was used to measure participants' resilience. The scale has been adapted and validated for the Greek population [32]. CD-RISC consists of 25 statements related to the characteristics of resilient individuals. Participants were asked to consider the last month and assess the truth of these statements using a 5-point Likert scale (where 1 means not true at all and five means almost always true). Scores range from zero to 100 , with higher scores 
suggesting greater resilience. In the present study, Cronbach's alpha is excellent $(\alpha=0.92)$. In previous studies Cronbach's alpha ranged between $\alpha=0.89$ and 0.93 [32,33].

Apart from the total score, Connor and Davidson (2003) [34] report five subscales; personal competence, high standards and tenacity (CD1), trust in one's instincts, tolerance of negative affect and strengthening effects of Stress (CD2), positive acceptance of change, and secure relationships (CD3), control (CD4) and spiritual influences (CD5). In the present study, Cronbach's alphas ranged from acceptable to excellent (for CD1 $\mathrm{a}=0.80$, for $\mathrm{CD} 2 \mathrm{a}=0.85$, for CD3 $\mathrm{a}=0.80$, for $\mathrm{CD} 4 \mathrm{a}=0.65$ and for CD5 $\mathrm{a}=0.74)$.

\section{Depression, Anxiety, and Stress.}

DASS 21, the short version of DASS 42 [35], was used to assess the level of participants' depression, anxiety, and stress. DASS 21 contains 21 statements and is designed to measure symptoms common in depression and anxiety. By using a 4point Likert scale (where zero means "never" and 4 means "almost always"), participants are called to consider the last week and to assess the presence or absence of symptoms during that time. The scale consists of three subscales; Depression (e.g., I could not seem to experience any positive feeling at all), anxiety (e.g., I was worried about situations in which I might panic and make a fool of myself), and stress (e.g., I found it difficult to relax). In previous studies in the general population, Cronbach's alpha for the three subscales ranged between 0.82 and 0.90 [36,35]. Cronbach's alpha was 0.94 for depression, 0.95 for anxiety, and 0.94 for stress in the present study.

\section{Fear of Covid-19}

The fear of Covid-19 scale (FCV-19S) [38] was used to assess possible negative feelings related to the Covid-19 pandemic. The scale has been adapted and validated for the Greek population [37]. The Greek version of the scale consists of 7 statements, and participants are asked to assess the level of their fear towards Covid-19 by using a 5-point Likert scale (where one means "totally disagree" and 5 means "totally agree"). The scores range from seven to 35, with higher scores indicating greater fear of Covid-19. In previous studies Cronbach's alpha ranged between 0.82 and 0.87 [28, 37-39]. In the present study, Cronbach's alpha was 0.84 .

\section{Cognitive functioning}

The Cognitive functioning self-assessment scale (CFSS) [40] was used to assess participants' cognitive functioning. CFFS contains 18 statements designed to assess the participant's cognitive functioning e.g., "I find it difficult to concentrate". Participants are asked to consider the last year and assess by using a 5-point Likert scale (where zero means "never" and 5 means "always") if they think that the statements depict their cognitive functioning. The scores range from 18 to 90 , with higher scores indicating lower levels of cognitive functioning. In previous studies, the internal consistency of the scale was found good [41]. In the present study, Cronbach's alpha was 0.9 .

\section{Statistical Analysis}

Data was analyzed using the IBM SPSS Statistics 22. Statical significant was considered at less than 0.05 . was used for data analysis. Descriptive statistics was recorded as percentage, mean and standard deviation. Bivariate analysis was performed using an independent Sample T-Test, Chi-Square Test, Oneway ANOVA, Mann-Whitney U Test, Kruskal-Wallis H Test, Spearman's Rank-Order Correlations, and Pearson productmoment correlations. In multivariate analysis the Simple Linear Regression was recruited to predict variables.

\section{Results}

The study's sample consisted of 88 members of the university's administrative staff (69 females). Thirty-one participants were young adults $(35.2 \%$, range $=25$ to 44 years $)$ and 57 were middle-aged adults $(64.8 \%$, range $=45$ to 65 years). Regarding their education level, 50 participants $(56.8 \%)$ held a postgraduate degree, $23(26.1 \%)$ were university graduates, and 15 (17.1\%) had completed upper secondary school. As far as it concerns their marital status, $54(61.3 \%)$ were married, 21 (23.9\%) were single, 10 (11.4\%) were divorced, and $3(3.4 \%)$ lived with a partner. Finally, 83 participants $(94.3 \%)$ stated that they had not been sick with Covid-19, while 5 (5.7\%) had been tested positive for Covid-19 (Table 1).

Table 1: sociodemographic characteristics $(\mathrm{n}=88)$

\begin{tabular}{|l|l|l|}
\hline Variables & Categories & $\mathbf{N}(\mathbf{\%})$ \\
\hline Age & 25 to 44 years & $31(35.2 \%)$ \\
\hline & 45 to 65 years & $57(64.8 \%)$ \\
\hline & Females & $69(78.4 \%)$ \\
\hline Marital status & Males & $19(21.6 \%)$ \\
\hline & Married & $54(61.3 \%)$ \\
\hline & Single & $21(23.9 \%)$ \\
\hline & Divorced & $10(11.4 \%)$ \\
\hline Education level & Lived with a partner & $3(3.4)$ \\
\hline & Post-graduate degree & $50(56.8 \%)$ \\
\hline $\begin{array}{l}\text { Diagnosed with } \\
\text { Covid-19 }\end{array}$ & $\begin{array}{l}\text { Upper secondary } \\
\text { school }\end{array}$ & $23(26.1 \%)$ \\
\hline & No & $15(17.1 \%)$ \\
\hline & Yes & $83(94.3 \%)$ \\
\hline
\end{tabular}

\section{Age-related differences}

An independent sample test and a Mann-Whitney U Test were run to find the differences by age group. Regarding age-related differences, our results suggest statistically significant agerelated differences in fear on Covid-19, care of personal hygiene, stress, and trust in government in Covid-related issues. More specifically, middle-aged adults had statistically significantly higher fear of Covid-19 $(16.21 \pm 5.69)$ compared to the young adults $(14.10 \pm 4.011), \mathrm{t}(80.165)=-2.027, P=$ 0.046 as well as more stress compared to the young adults, $\mathrm{U}=648.500, \mathrm{p}=0.040$, with a mean rank of 36.92 for the young adults and 48.62 for the middle-aged adults. Furthermore, a statistically significant association between age and confidence in the government's official updates was found $(\chi 2(3)=9.476$, $P=0.024)$. The strength of association between age and confidence in the government's official updates is moderate $(\varphi c$ $=0.328)$. Finally, there is a statistically significant association between age and care of personal hygiene $\left(\chi^{2}(2)=14.025, P=\right.$ $0.001)$. The strength of association between age and care of personal hygiene is moderate $(\varphi c=0.399)$. 
Gender-related differences

Concerning gender-related differences, Mann-Whitney U Test analysis suggests that women had statistically significantly restricted their physical contact compared to men, $\mathrm{U}=485.500$, $P=0.042$, with a mean rank of 35.55 for men and 46.96 for women. Moreover, a statistically significant association between gender and restriction of physical contact was also found $\left(\chi^{2}(1)=5.457, P=0.019\right)$. The strength of association between gender and restriction of physical contact is weak $(\varphi c$ $=0.249$ ). On the other hand, we found that men trusted statistically significantly more the results of clinical trials of Covid-19 vaccines than women, $\mathrm{U}=459.500, \mathrm{p}=0.039$, with a mean rank of 54.82 for men 41.66 for women.

\section{Marital Status}

One-Way ANOVA analysis suggests that marital status relates both with restricting physical contact during the Covid-19 pandemic and resilience levels. In detail, there was a statistically significant difference in restriction of physical contact between the groups of marital status, $\chi 2(3)=8.712, p=$ 0.033 , with a mean rank of 40.52 for singles, 47.44 for married, 46.80 for divorced, and 11.67 for those who live with others. Dunn's pairwise tests were carried out for the four pairs of groups. Married had statistically significant restricted physical contact more than those living with others, $\mathrm{p}=0.032$, (adjusted using the Bonferroni correction). Moreover, there was a statistically significant difference in CD-RISC between the marital status groups as determined by one-way ANOVA, F (3, $81)=3.271, P=0.025$. A Tukey post hoc test revealed that CDRISC was statistically significantly lower for singles $(91.57 \pm$ 12.5, $P=0.027)$ and married $(92.02 \pm 12.52, P=0.016)$ compared to divorced $(105.88 \pm 6.66)$.

\section{Recovery from Covid-19}

Finding of Mann-Whitney U Test showed that Those who have become infected by Covid-19 check themselves for symptoms of Covid-19 statistically significantly more compared to those who have not become infected by Covid-19, U=93.500, $P=$ 0.033 , with a mean rank of 43.13 for those who have not become infected by Covid-19 and 67.30 for those who have become infected by Covid-19.

The relationship between fear of Covid-19, negative affect, resilience, and cognitive functioning and trust Spearman's rank-order correlations were run to determine the relationship between fear of Covid-19, negative affect, resilience, and cognitive functioning. More specifically, a weak but statistically significant negative correlation was found between resilience on the one hand and fear of Covid-19 and depression on the other hand (all ps < 0.05). Moreover, moderate negative correlations were found between resilience on the one hand and anxiety and stress on the other hand (all ps $<0.05$ ). Concerning the fear of Covid-19, results suggest weak but statistically significant correlations with cognitive deficits and anxiety and moderate correlations with depression and stress (all ps < 0.05). Furthermore, cognitive deficits positively correlate with depression (moderate), anxiety (weak), and stress (moderate) (all ps < 0.05). Finally, results suggest a moderate positive correlation between trust in media (as a source of information) and fear of Covid-19, (Table 2).
The relationship between resilience and cognitive functioning

A series of Pearson product-moment correlations were run to determine the relationship between $\mathrm{CD}$ and its subscales with cognitive functioning (see Table 3). There was a moderate, negative correlation between $\mathrm{CD}$ and cognitive functioning (e.g., in terms of cognitive deficits), which was statistically significant, $\mathrm{r}=-0.412, \mathrm{n}=87, \mathrm{p}<0.001$. Furthermore, a simple linear regression was used to predict cognitive functioning from CD. CD explains an amount of the variance in cognitive functioning, $\mathrm{F}(1,85)=17.331, \mathrm{p}<0.001, \mathrm{R} 2=0.169$, adjusted $\mathrm{R} 2=0.160$. The regression coefficient, $\mathrm{B}=-0.287$, indicated that an increase of one in CD corresponded, on average, to a decrease in cognitive functioning of 0.287 . Moreover, there was a moderate, negative correlation between $\mathrm{CD} 1$ and cognitive functioning (e.g., in terms of cognitive deficits), which was statistically significant, $\mathrm{r}=-0.560, \mathrm{n}=83, \mathrm{p}<0.001$. Furthermore, a simple linear regression was used to predict cognitive functioning from CD1. CD1 explains an amount of the variance in cognitive functioning, $\mathrm{F}(1,81)=37.095$, $\mathrm{p}<$ $0.001, \mathrm{R} 2=0.314$, adjusted $\mathrm{R} 2=0.306$. The regression coefficient, $\mathrm{B}=-.961$, indicated that an increase of one in CD1 corresponded, on average, to a decrease in cognitive functioning of 0.961 .

\section{Discussion}

The current cross-sectional study aimed to examine the associations between resilience, fear of Covid-19, mood (depression, anxiety, stress), and cognitive functioning in the administrators of the University of Western Macedonia. At first, the present study found that resilience relates to fear of Covid19, negative affect, and cognitive functioning according to the predictions that derive from the respective literature. As far as it concerns the perceived cognitive functioning, there was a connection between resilience and cognitive functioning. This means that the better cognitive functioning someone believes she/he has, the more resilient she/he is. There are research studies that have investigated cognitive functioning and the effects of Covid-19. Cognitive deficits such as memory impairment and possible long-term neurological consequences were observed [25-27]. However, to our knowledge, no study relates cognitive deficits during the Covid-19 pandemic with resilience.

The relationship between cognitive functioning, anxiety, and stress showed a connection between perceived cognitive functioning and anxiety and stress. The better cognitive functioning someone believes she/he has, the less anxiety and stress she/he has. These findings are per studies suggesting higher levels of cognitive functioning to be associated with higher levels of resilience in healthy adults [42]. In addition, stress and anxiety caused by significant life events (such as Covid-19) have a documented harmful impact on cognitive processes and functioning [43]. Furthermore, the findings of this study report a significant relationship between Covid-19 related fear and stress. As Nikčević and Spada [44] suggest, the pandemic outbreak has profoundly changed the way we live, increasing pandemic-related distress. Previous research data in a Greek population also present a moderate to severe anxiety impact on most participants [45]. 
Table 2: Descriptive Statistics and Spearman's Rank-Order Correlations

\begin{tabular}{|c|c|c|c|c|c|c|c|c|c|c|c|c|c|}
\hline Variable & $\mathrm{n}$ & $\mathrm{M}$ & $\mathrm{SD}$ & 1 & 2 & 3 & 4 & 5 & 6 & 7 & 8 & 9 & 10 \\
\hline 1. FCV-19S & 88 & 15.47 & 5.24 & - & & & & & & & & & \\
\hline 2. Depression & 88 & 10.43 & 8.72 & $.44 * *$ & - & & & & & & & & \\
\hline 3. Anxiety & 88 & 11.70 & 9.29 & $.39 * *$ & $.94 * *$ & - & & & & & & & \\
\hline 4. Stress & 88 & 9.30 & 8.78 & $.45 * *$ & $.91 * *$ & $.93 * *$ & - & & & & & & \\
\hline 5. CD-RISK & 88 & 92.20 & 13.83 & $-.26^{*}$ & $-.36 * *$ & $-.40 * *$ & $-.43 * *$ & - & & & & & \\
\hline 6. CD1 & 88 & 30.33 & 4.76 & $-.26^{*}$ & $-.30 * *$ & $-.37 * *$ & $-.42 * *$ & $.91 * *$ & - & & & & \\
\hline 7. CD2 & 88 & 24.84 & 4.96 & $-.27 *$ & $-.33 * *$ & $-.38 * *$ & $-.42 * *$ & $.91 * *$ & $.78 * *$ & - & & & \\
\hline 8. CD4 & 88 & 11.38 & 2.03 & $-.32 * *$ & $-.42 * *$ & $-.44 * *$ & $-.43 * *$ & $.74 * *$ & $.64 * *$ & $.67 * *$ & - & & \\
\hline 9. CFSS & 88 & 40.32 & 8.88 & $.21 *$ & $.37 * *$ & $.45 * *$ & $.48 * *$ & $-.42 * *$ & $-.44 * *$ & $-.44 * *$ & $-.36 * *$ & - & \\
\hline $\begin{array}{l}\text { 10. Trust in the news of } \\
\text { the TV channels }\end{array}$ & 88 & - & - & $.43 * *$ & -.03 & -.09 & -.03 & .00 & .07 & -.04 & -.02 & -.05 & - \\
\hline
\end{tabular}

Moreover, other international studies already underscore the moderate to severe levels of stress effects as a reaction to the Covid-19 experience [46,47]. Furthermore, research data show that anxiety levels after lockdown remain markedly higher than before lockdown levels. The consequences of this situation in work and social interactions are yet to be known [48]. In all, the Covid-19 outbreak is expected to cause increased levels of anxiety [49]. Considering that those suffering from Covid-19 related fear may also exhibit increased general stress, health anxiety, and post-traumatic stress [50,51], which might last long after the pandemic, the return to normal functioning might be more difficult for some individuals. Therefore, the early identification of increased levels of pandemic-related stress may lead to early use of stress-reducing interventions to alleviate the psychological impact in the University of Western Macedonia administrators and possibly reduce the likelihood of this a longterm occurrence.

Table 3: Simple Linear Regression

\begin{tabular}{|l|l|l|l|l|l|}
\hline Source & $\mathrm{B}$ & $\mathrm{SE}$ & $\beta$ & $\mathrm{t}$ & $\mathrm{p}$ \\
\hline 1. CD-RISK & -0.287 & 0.069 & -0.412 & -4.163 & $<0.01$ \\
\hline 2. CD1 & -0.961 & 0.158 & -0.560 & -6.091 & $<0.01$ \\
\hline 3. CD2 & -0.863 & 0.163 & -0.512 & -5.296 & $<0.01$ \\
\hline
\end{tabular}

Dependent variable: Cognitive functioning

Moreover, there was a statistically significant positive correlation between fear of Covid-19 and depressive symptoms. This finding agrees with other reports showing the increased prevalence rate of depression during the pandemic [52]. Past research data already indicate that the length and uncertainty of a lockdown can contribute to higher rates of depressive symptoms [53]. Therefore, the measures are already taken can explain higher levels of depression during the Covid-19 outbreak as depression is an anticipated reaction to an abrupt worsening of everyday life. As safety behaviors have been linked with higher levels of psychological distress [54], this study also examined the use of two safety behaviors: taking care of personal hygiene and keeping a minimum social distance [45]. Gender seemed to play an important role as women tended to take care of personal hygiene more regularly compared to men. In addition, women restricted physical contact more than men. These results echo this study's women's' anticipation of a negative impact of the pandemic on their health or the health of loved ones. The fear of Covid-19 transmission during the pandemic is connected with precautionary measures and self- restraint behaviors to prevent infection. Our findings coincide with previous studies reporting female gender as significantly related to considerable psychological impact due to the pandemic outbreak and increased levels of stress, anxiety, and depression $[47,55]$. Finally, our results suggest some age-related differences in the psychological impact of the pandemic. More specifically, in our study, middle-aged adults stated that they have higher levels of fear of Covid-19, better care of personal hygiene, higher levels of stress, and more trust in the government in Covid-related issues than young adults. These results are in line with previous research findings in the Greek population showing that younger participants (aged 18-30 years) reported less fear and depressive symptomatology than older age categories, as well as that respondents over the age of 46 , were more careful of their personal hygiene than younger respondents [45]. It is well documented that for older adults, Covid-19 is considered a life-threatening disease to a greater extent than in younger age groups. Thus, we assume that fear of contracting Covid-19 and consequently negative effect and compliance with safety restrictions might be greater in older participants than younger age groups.

As several research focused on professional fields, we selected a category of employees that seemed to be particularly affected by the conditions imposed due to Covid-19 (e.g., teleworking, distance learning, support of the University services). In addition, we hope that the combination of these important variables will further illuminate their interactions. The ultimate goal is to plan interventions that will support employees in these challenging conditions. The originality of this study lies in the investigation of important variables in pandemic conditions in a specific group of employees within the university. It is worth noting that there are no similar studies in Western Macedonia, and regarding the administrative staff within the university, there is no corresponding research nationwide. The moderate sample size and the homogeneity of the participants should be considered about the applicability of the results. It should also be noted that the results of this study were grounded on self-report measures subject to social desirability and self-report errors. As the academic scene is rapidly changing due to the COVID-19 pandemic, new skills and increased adaptability are needed by the administrative staff to deal successfully with new emerging challenges while operating under urgent procedures. Thus, more studies are needed by other Greek Universities from different geographical 
regions for the results to be compared and, therefore, more generalizable.

\section{Conclusion}

The results of this study showed that it is crucial to continue monitoring the psychological reactions during the Covid-19 pandemic to help both healthcare workers emphasize the most vulnerable group of people and policymakers to design evidence-based interventions for this stressful event

\section{Abbreviation}

CD-RISC: Connor-Davidson Resilience Scale; CD1: ConnorDavidson 1-personal competence, high standards, and tenacity; CD2: Connor-Davidson 2-trust in one's instincts, tolerance of negative affect and strengthening effects of stress; CD3: Connor-Davidson 3-positive acceptance of change, and secure relationships; CC4: Connor-Davidson 4- control; CD5: ConnorDavidson 5-spiritual influences; DASS: Depression, Anxiety, and Stress; FCV-19S: Fear of Covid-19. The fear of Covid-19 scales; CFSS: Cognitive functioning self-assessment scale

\section{Declaration}

Acknowledgment

None.

\section{Funding}

The authors received no financial support for their research, authorship, and/or publication of this article.

\section{Availability of data and materials}

Data will be available by emailing katerinaflora@hotmail.com.

\section{Authors' contributions}

All authors have contributed equally to the original draft's study concept, design, writing of the original draft. All authors read and approved the final manuscript.

\section{Ethics approval and consent to participate}

We conducted the research following the Declaration of Helsinki. Ethical approval was obtained from Research Ethics Committee of University of Western Macedonia, Greece (approval number: 24/2021). Informed consent was also obtained from students before data collection through WhatsApp messages. Anonymity was maintained in the questionnaire as well.

\section{Consent for publication}

Not applicable

\section{Competing interest}

The authors declare that they have no competing interests.

\section{Open Access}

This article is distributed under the terms of the Creative Commons Attribution $\quad 4.0 \quad$ International License (http://creativecommons.org/licenses/by/4.0/), which permits unrestricted use, distribution, and reproduction in any medium, provided you give appropriate credit to the original author(s) and the source, provide a link to the Creative Commons license, and indicate if changes were made. The Creative Commons Public Domain Dedication waiver (http://creativecommons.org/publicdomain/zero/1.0/) applies to the data made available in this article, unless otherwise stated.

\section{Author Details}

${ }^{1}$ Department of Psychology, University of Western Macedonia, Florina, Greece.

Article Info

Received: 07 August 2021

Accepted: 07 September 2021

Published: 30 September 2021

\section{References}

1. Luthar SS. Resilience in Development: A Synthesis of Research across Five Decades. 2006; In D. Cicchetti, \& D. J. Cohen (Eds.), Developmental Psychopathology: Risk, Disorder, and Adaptation (pp. 739-795). New York: Wiley.

2. Luthar SS, Ebbert AM, Kumar NL. Risk and resilience during COVID-19: A new study in the Zigler paradigm of developmental science. Development and Psychopathology. 2020; 1-16. https://doi.org/10.1017/S0954579420001388

3. Masten AS. Resilience in developing systems: Progress and promise as the fourth wave rises. Development and Psychopathology.2007; 19 : 921-930. doi:10.1017/S0954579407000442

4. Masten A, Tellegen A. Resilience in developmental psychopathology: Contributions of the Project Competence Longitudinal Study. Development and Psychopathology.2012; 24: 345 - 361.

5. Garmezy N. Development and adaptation: The contributions of the MacArthur Foundation and William Bevan. 1995; In Kessel F, editor. Psychology, science, and human affairs: Essays in Honor of William Bevan. Westview Press; Boulder, CO: 1995; 109-124.

6. Rutter M, Maughan B, Mortimore P, Ouston, J. Fifteen thousand hours: School influences on pupil progress: research strategies and tactics. Journal of Child Psychology and Psychiatry. 1979b; 2(4): 366-8.

7. Werner E, Smith R. Vulnerable but invincible: A longitudinal study of resilient children and youth. 1982; New York: Adams, Bannister, and Cox.

8. Cowen EL. The enhancement of psychological wellness: Challenges and opportunities. American Journal of Community Psychology.1994; 2(2): 149-179

9. Masten AS, Wright MO. Cumulative Risk and Protection Models of Child Maltreatment. Journal of Aggression, Maltreatment \& Trauma. 2008; 2(1):7-30

10. Wright MOD, Masten AS, Narayan AJ. Resilience processes in development: Four waves of research on positive adaptation in the context of adversity. 2013; In S. Goldstein, \& R. B. Brooks (Eds.), Handbook of Resilience in Children: Second Edition (2nd Edition ed. 15-37). Springer US. https://doi.org/10.1007/978-1-4614-3661-4_2

11. Crum AJ, Akinola M, Martin A, Fath S. The role of stress mindset in shaping cognitive, emotional, and physiological responses to challenging and threatening Stress. Anxiety Stress \& Coping. 2017; 30(4): 379-395. https://doi.org/10.1080/10615806.2016.1275585.

12. Barzilay R, Moore TM, Greenberg DM, DiDomenico GE, Brown LA, White LK, Gur RC, Gur RE. Resilience, COVID-19-related stress, anxiety, and depression during 
the pandemic in a large population enriched for healthcare providers. Translational Psychiatry. 2020; 10(1): 291. https://doi.org/10.1038/s41398-020-00982-4

13. Bozdăg F, Ergün N. Psychological Resilience of Healthcare Professionals During COVID-19 Pandemic. Psychological Reports, 2020; 33294120965477. https://doi.org/10.1177/0033294120965477

14. Rahman MA, Hoque N, Alif SM, Salehin M, Islam SMS, Banik B, et al. Factors associated with psychological distress, fear and coping strategies during the COVID-19 pandemic in Australia, Globalization and Health. 2020; 16 (95).https://doi.org/10.1186/s12992-020-00624-w

15. Nguyen L, Drew D, Graham M, Joshi A, Guo C, Ma W et al. Risk of COVID-19 among front-line healthcare workers and the general community: a prospective cohort study. Lancet Pub Health, 2020; 5(9): 475-83. https://doi.org/10.1016/S2468-2667(20)30164-X

16. Rodríguez-Hidalgo, A J, Pantaleón Y, Dios I, Falla D. Fear of COVID-19, Stress, and Anxiety in University Undergraduate Students: A Predictive Model for Depression. Frontiers in Psychology. 2020; 11:591797, https://doi.org/10.3389/fpsyg.2020.591797

17. Riaz M, Abid M, Bano Z. Psychological problems in the general population during covid-19 pandemic in Pakistan: role of cognitive emotion regulation. Annals of Medicine. 2021; $53 \quad$ (1): $189-196, \quad$ https://doi.org/ $10.1080 / 07853890.2020 .1853216$.

18. Mertens G, Gerritsen L, Duijndam S, Salemink E, Engelhard IM. Fear of the coronavirus (COVID-19): Predictors in an online study conducted in March 2020. Journal of Anxiety Disorders. 2020; 74, 102258. https://doi.org/10.1016/j.janxdis.2020.102258

19. Levkovich I, Shinan-Altman S. Impact of the COVID-19 pandemic on stress and emotional reactions in Israel: a mixed-methods study. International Health. 2020; ihaa081. https://doi.org/10.1093/inthealth/ihaa081

20. Labrague LJ, de Los Santos J. Fear of COVID-19, psychological distress, work satisfaction and turnover intention among frontline nurses. Journal of Nursing Management. 2020; 10.1111/jonm. 13168 . https://doi.org/10.1111/jonm.13168

21. Alexopoulos P, Soldatos R, Kontogianni E, Frouda M, Aligianni S, Skondra M, et al. COVID-19 Crisis Effects on Caregiver Distress in Neurocognitive Disorder. Journal of Alzheimer's Disease. 2021; 79(1): 459-466. https://doi.org/10.3233/JAD-200991

22. Bertsias A, Symvoulakis E, Tziraki C, Panagiotakis S, Mathioudakis L, Zaganas I, et al. Cognitive impairment and dementia in primary care: current knowledge and future directions based on findings from a large crosssectional study in Crete, Greece. Frontiers in Medicine. 2020; 7 , 592924. https://doi.org/10.3389/fmed.2020.592924

23. Borges-Machado F, Barros D, Ribeiro Ó, Carvalho J. The effects of COVID-19 home confinement in dementia care: physical and cognitive decline, severe neuropsychiatric symptoms and increased caregiving burden. American Journal of Alzheimer's Disease \& Other Dementias. 2020; 35 , 1533317520976720 . https://doi.org/10.1177/1533317520976720
24. Tsapanou A, Papatriantafyllou JD, Yiannopoulou K. et al. The impact of COVID-19 pandemic on people with mild cognitive impairment/dementia and on their caregivers. International Journal of Geriatric Psychiatry. 2020; 1-5. https://doi.org/ 10.1002/gps.5457

25. Hampshire A, Trender W, Chamberlain SR, Jolly A, Grant JE, Patrick F, et al. Cognitive deficits in people who have recovered from COVID-19 relative to controls: An $\mathrm{N}=84,285$ online study. medRxiv preprint. 2020; https://doi.org/10.1101/2020.10.20.20215863

26. Miners S, Kehoe PG, Love S. Cognitive impact of COVID-19: looking beyond the short term. Alzheimer's Research \& Therapy. 2020; 12(1): 170. https://doi.org/10.1186/s13195-020-00744-w

27. Ritchie K, Chan D. Watermeyer T. The cognitive consequences of the COVID-19 epidemic: collateral damage? Brain Communications.2020; 2(2): [fcaa069]. https://doi.org/10.1093/braincomms/fcaa069

28. Nikopoulou VA, Holeva V, Parlapani E, Karamouzi P, Voitsidis P, Porfyri GN, et al. Mental Health Screening for COVID-19: a Proposed Cutoff Score for the Greek Version of the Fear of COVID-19 Scale (FCV-19S). International Journal of Mental Health and Addiction. 2020; 1-14. Advance online publication. https://doi.org/10.1007/s11469-020-00414-w

29. Peppou LE, Economou M, Skali T, Papageorgiou C. From economic crisis to the COVID-19 pandemic crisis: evidence from a mental health helpline in Greece. European Archives of Psychiatry and Clinical Neuroscience. 2020; https://doi.org/10.1007/s00406-02001165-4

30. Magklara K, Lazaratou H, Barbouni A, Poulas K, Farsalinos K. Impact of COVID-19 pandemic and lockdown measures on mental health of children and adolescents in Greece. medRxiv preprint. 2020; https://doi.org/10.1101/2020.10.18.20214643

31. Vatavali F, Gareiou Z, Kehagia F, Zervas E. Impact of COVID-19 on urban everyday life in Greece: perceptions, experiences and practices of the active population. Sustainability. 2020; 12(22) :2-17, 9410 https://doi.org/10.3390/su12229410

32. Tsigkaropoulou E, Douzenis A, Tsitas N, Ferentinos P, Liappas I, Michopoulos. Greek version of the ConnorDavidson resilience scale: psychometric properties in a sample of 546 subjects. In vivo. 2018; 32(6): 1629-1634. https://doi.org/10.21873/invivo.11424

33. Baek HS, Lee KU, Joo EJ, Lee MY, Choi KS. Reliability and validity of the Korean version of the Connor-Davidson resilience scale. Psychiatry Investigation. 2010; 7(2): 109 115.https://doi.org/10.4306/pi.2010.7.2.109

34. Connor KM, Davidson J R. Development of a new resilience scale: the Connor-Davidson Resilience Scale (CD-RISC). Depression \& Anxiety. 2003; 18(2): 76-82. https://doi.org/10.1002/da.10113

35. Lovibond PF, Lovibond SH. The structure of negative emotional states: comparison of the Depression Anxiety Stress Scales (DASS) with the Beck Depression and Anxiety Inventories. Behaviour Research and therapy. 1995; 33(3): 335-343. https://doi.org/00057967(94)00075-u 
36. Lee D. The convergent, discriminant, and nomological validity of the Depression Anxiety Stress Scales-21 (DASS-21). Journal of Affective Disorders. 2019; 259: 136-142.https://doi.org/10.1016/j.jad.2019.06.036

37. Tsipropoulou V, Nikopoulou VA, Holeva V, Nasika Z, Diakogiannis I, Sakka S, et al. Psychometric properties of the Greek version of FCV-19S. International Journal of Mental Health and Addiction. 2020;1-10. https://doi.org/10.1007/s11469-020-00319-8

38. Ahorsu DK, Lin CY, Imani V, Saffari M, Griffiths MD, Pakpour AH. The fear of COVID-19 Scale: development and initial validation. International Journal of Mental Health and Addiction. 2020; 1-9. https://doi.org/10.1007/s11469-020-00270-8

39. Soraci P, Ferrari A, Abbiati FA, Del Fante E, De Pace R, Urso A , Griffiths MD. Validation and psychometric evaluation of the Italian version of the Fear of COVID-19 Scale. International Journal of Mental Health and Addiction. 2020; 1-10. https://doi.org/10.1007/s11469020-00277-1

40. Annunziata MA, Muzzatti B, Giovannini L, Lucchini G. Cognitive functioning self-assessment scale (CFSS): preliminary psychometric data. Psychology. Health \& Medicine. 2012; 17(2): 207-212. https://doi.org/10.1080/13548506.2011.596552

41. Annunziata MA, Muzzatti B, Flaiban C, Giovannini L, Lucchini G. Cognitive Functioning Self-Assessment Scale (CFSS): Further psychometric data. Applied Neuropsychology: Adult. 2018; 25(1), 1-4. https://doi.org/10.1080/23279095.2016.1225575

42. Deng M, Pan Y, Zhou L, Chen X, Liu C, Huang X, et al. Resilience and cognitive function in patients with schizophrenia and bipolar disorder, and healthy controls. Frontiers in Psychiatry. 2018; 9 (279). https://doi.org/10.3389/fpsyt.2018.00279

43. Lukasik KM, Waris O, Soveri A, Lehtonen M, Laine M. The Relationship of anxiety and stress with working memory performance in a large non-depressed sample. Frontiers in psychology. 2019; $10 \quad$ (4). https://doi.org/10.3389/fpsyg.2019.00004

44. Nikčević AV, Spada MM. The COVID-19 anxiety syndrome scale: Development and psychometric properties. Psychiatry Research. 2020; 292, 113322. https://doi.org/10.1016/j.psychres.2020.113322

45. Parlapani E, Holeva V, Voitsidis P, Blekas A, Gliatas I, Diakogiannis I. Psychological and behavioral responses to the COVID-19 pandemic in Greece. Frontiers in Psychiatry. 2020; (821).https://doi.org/10.3389/fpsyt.2020.00821

46. Allington D, Duffy B, Wessely S, Dhavan N, Rubin J. Health-protective behaviour, social media usage and conspiracy belief during the COVID-19 public health emergency. Psychological Medicine. 2020; 1-7. https://doi.org/10.1017/S003329172000224X

47. Wang C, Pan R, Wan X, Tan Y, Xu L, Ho CS, Ho RC. Immediate psychological responses and associated factors during the initial stage of the 2019 coronavirus disease (COVID-19) epidemic among the general population in China. International Journal of Environmental Research and Public Health. 2020; 17(5): 1729. https://doi.org/10.3390/ijerph17051729

48. Allington D, Beaver K, Duffy B, Meyer C, Moxham-Hal $\mathrm{V}$, Murkin $\mathrm{G}$, et al. The trusting, the dissenting and the frustrated: how the UK is dividing as lockdown is eased. Kings' College London Policy Feb 2021; Institute. https://www.kcl.ac.uk/policy-institute/assets/how-the-ukis-dividing-as-the-lockdown-is-eased.pdf

49. Fardin MA. COVID-19 and anxiety: a review of psychological impacts of infectious disease outbreaks. archives of clinical infectious diseases. 2020; e102779. https://doi.org/10.5812/archcid.102779

50. Wheaton MG, Abramowitz JS, Berman NC, Fabricant LE, Olatunji BO. Psychological predictors of anxiety in response to the H1N1 (Swine Flu) pandemic. Cognitive Therapy and Research. 2011; 36(3): 210-218. https://doi.org/10.1007/s10608-011-9353-3

51. Yip PS, Cheung YT, Chau PH, Law YW. The impact of epidemic outbreak: the case of severe acute respiratory syndrome (SARS) and suicide among older adults in Hong Kong. Crisis. 2010; 31(2): $86-$ 92.https://doi.org/10.1027/0227-5910/a000015

52. Bueno-Notivol J, Gracia-García P, Olaya B, Lasheras I, López-Antón R, Santabárbara J. Prevalence of depression during the COVID-19 outbreak: A meta-analysis of community-based studies. International Journal of Clinical and Health Psychology. 2021; 21(1), 100196. https://doi.org/10.1016/j.ijchp.2020.07.007

53. Hawryluck L, Gold WL, Robinson S, Pogorski S, Galea S, Styra R. SARS control and psychological effects of quarantine, Toronto, Canada. Emerging Infectious Diseases. 2004; 10(7): 1206-1212. https://doi.org/10.3201/eid1007.030703

54. Lee SA, Jobe MC, Mathis AA, Gibbons JA. Incremental validity of coronaphobia: Coronavirus anxiety explains depression, generalized anxiety, and death anxiety. Journal of Anxiety Disorders. 2020; 74, 102268. https://doi.org/10.1016/j.janxdis.2020.102268

55. Broche-Pérez Y, Fernández-Fleites Z, Jiménez-Puig E, Fernández-Castillo E, Rodríguez-Martin BC. Gender and Fear of COVID-19 in a Cuban Population Sample. International Journal of Mental Health and Addiction. 2020; 1-9. https://doi.org/10.1007/s11469-020-00343-8 